Buana Sains Vol 19 No 1 : 69-80, 2019

\title{
PERMUKIMAN TRADISIONAL DI KAWASAN LANSKAP PANTAI DI SENDIKI, DESA TAMBAKREJO KECAMATAN SUMBERMANJING WETAN KABUPATEN MALANG
}

\author{
Irawan Setyabudi dan Petrus Paulus Pain Pati
}

Fakultas Pertanian, Universitas Tribhuwana Tunggadewi

\begin{abstract}
Traditional settlements are places that still hold customary and cultural values related to beliefs or religion that are specific or unique to a particular society. In each region of Nusantara there are various cultures, and in it there are traditional settlements as identities. This research is located in the Sendiki beach area which is a tourist attraction in the southern Malang district, precisely in the village of Tambakrejo. The problem is the diminishing public awareness in preserving the existence of settlement forms because of the current of modernization. The unique settlement pattern model in the village of Tambakrejo lined up along the road following the traditional settlement pattern of Tanean Lanjeng, because the settlements were dominated by Madura race. On the other hand because it is located in East Java, the formation of his house was also adapted to the building form of joglo. Another problem is the low public awareness in maintaining environmental quality which impacts the degradation of ecosystem quality. The aims of this research include identifying the architectural forms of houses, landscapes and traditional settlements in the village of Tambakrejo, as an effort to preserve them. The research method was conducted qualitatively by analyzing the data using Focus Group Discussion (FGD). The research thinking is adapted to the ideas of Rapoport. The stages of research start from the identification of physical, biophysical, socio-cultural and economic aspects, to the description of analysis and synthesis in settlement patterns and traditional homes. The results obtained in the form of a description of traditional settlement patterns, the formation of residential architecture and landscape patterns of settlements. The conclusions of this study include documentation of traditional architecture, landscapes and settlements as knowledge to respect the natural environment and culture of the people living.
\end{abstract}

Keywords: Coastal landscape area; Sendiki beach; Tambakrejo Village; traditional settlements; Malang

\section{Pendahuluan}

Indonesia adalah negara kepulauan yang memiliki garis pantai yang panjang dan memiliki karakteristik yang unik. (Van Der Zanden dan Rodie, 2008). Kawasan laut dan pesisir di Jawa Timur memiliki luas sekitar dua kali luas daratan $\left(+47.220 \mathrm{~km}^{2}\right)$ dan memiliki garis pantai sepanjang sekitar $2000 \mathrm{~km}$ yang aktif dan berpotensi.

Wilayah pantai Sendiki adalah contoh salah satu pantai di Kabupaten Malang yang memiliki permasalahan lingkungan, seperti akses sirkulasi yang kurang layak dan dapat mengganggu 
aktivitas pelaku pengunjung, rusaknya habitat terumbu karang sebagai rumah bagi biota laut, dan adanya pengikisan pantai atau abrasi. Hal tersebut berkiatan dengan aspek ekowisata seperti konservasi alam, sosial budaya dan ekonomi masyarakat setempat serta pendidikannya.

Masyarakat setempat masih dapat dikategorisasikan sebagai masyarakat tradisional yang memiliki lingkungan masih selaras dengan alam. Rumah yang memiliki arsitektur khas tradisional sesuai dengan budaya masyarakat tersebut, yaitu suku Madura yang tinggal di kawasan pantai Sendiki. Keunikannya adalah adaptasi bentukan rumah Madura namun ada di Malang Selatan. Permasalahannya adalah secara mikro, eksistensi aksen tipologi rumah akan tergeser tidak lagi menjadi rumah tradisional karena masuknya berbagai budaya yang masuk karena open-mind sebagai daerah wisata, dalam konteks meso-makro, atau lingkup lanskap dan permukiman dampaknya akan lebih luas lagi.
Kajian ini bermaksud mengidentifikasi dan merekam bentukan arsitektur dan lingkungan masyarakat Kawasan Pantai Sendiki agar menjadi pembelajaran dan dapat digunakan secara turun-temurun.

\section{Metode Penelitian}

Lokasi penelitian berada di pantai Sendiki Desa Tambakrejo, Kabupaten Malang. Metode penelitian dilakukan secara kualitatif, dengan analisis data melalui Focus Group Discussion (FGD). Hasil diskusi tersebut melahirkan konsep pemikiran tentang permukiman tradisional yang dituliskan secara deskriptif. Tahapan penelitian dilakukan dengan persiapan awal, identifikasi fisik, biofisik, sosial, budaya dan ekonomi. Hasil analisis berupa identifikasi pola permukiman tradisional, lanskap dan arsitektur rumah tinggal.

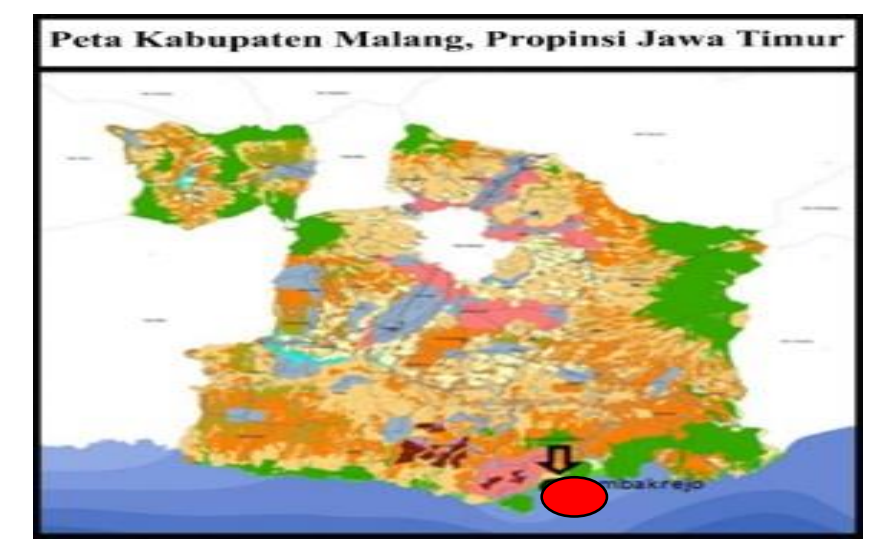

Gambar 1. Peta Kabupaten Malang

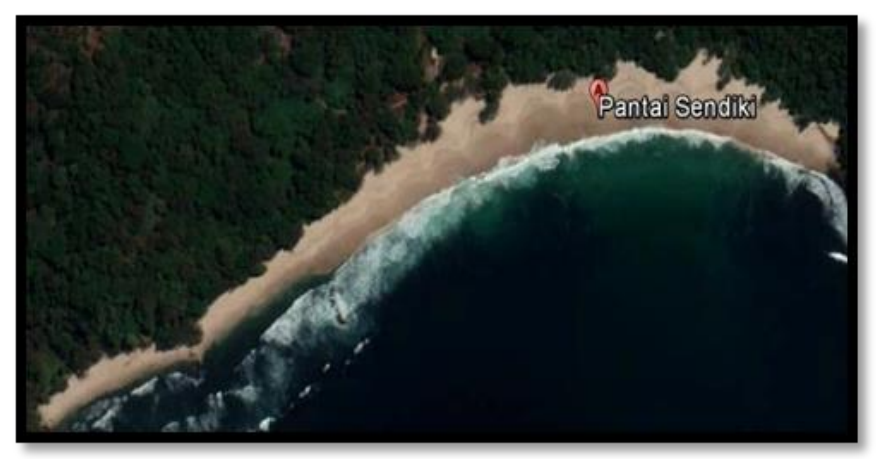

Gambar 2. Lokasi Penelitian 


\section{Hasil dan Pembahasan}

Berdasarkan hasil penelitian yang dilakukan bahwa Desa Tambakrejo kecamatan Sumbermanjing Wetan Kabupaten Malang, Jawa Timur terdapat 3 Dusun atau Dukuh yang membawahi Desa Tambakrejo tersebut, yakni Sendang biru, Tamban dan Tambakrejo. Dari ketiga dusun atau dukuh tersebut masing-masing memiliki potensi alam dan sumber daya alam yang berbeda dan dijadikan sebagai industri pariwisata yaitu berupa pantai. Dusun Sendang Biru memiliki obyek wisata pantai yakni Pantai Sendang Biru, Dusun Tamban memiliki obyek wisata pantai berupa Pantai Tamban Indah dan Pantai Sendiki, sedangkan Dusun Tambakrejo memiliki obyek wisata berupa Pantai Sendiki yang dijadikan sebagai lokasi penelitian.

Mayoritas penduduk di ketiga dusun tersebut berbeda, didusun sendang biru, mayoritas penduduknya yakni suku Bugis dan sebagian suku Madura, di dusun Tamban mayoritas penduduknya adalah penduduk asli setempat yakni dari Desa Sitiarjo dan Desa Tambakrejo, sedangkan di Dusun Tambakrejo itu sendiri mayoritas penduduknya yakni berasal dari suku Madura dan sebagian penduduknya adalah penduduk atau masyarakat pendatang yang telah lama bermukim disusun Tambakrejo tersebut serta penduduk asli Desa Tambakrejo. Adapun Pola sosialisasi atau pemukiman tersebut didasarkan atas pelakunya, yaitu laki-laki, perempuan dan anak-anak. Aktivitas bersama yang terjadi antara lain antara sesama perempuan, perempuan dan anak-anak atau aktivitas mengasuh, aktivitas bersama antara sesama laki-laki, aktivitas bersama semua (laki-laki, perempuan, dan anak-anak), dan aktivitas bersama. Pola permukiman lanskap yang terjadi di dukuh Tambakrejo Desa Tambakrejo Kabupaten Malang yakni mengadopsi pola permukiman suku madura perantauan yakni (Madura Medalungan) yang membawa tradisi berhuninya ke daerah yang baru. Salah lokasi perantauan masyarakat Madura di Jawa Timur adalah dukuh Tambakrejo, selain itu juga dapat ditemukan di Kota Malang yaitu permukiman daerah Buring, juga mengadopsi dari Madura Medalungan. Dengan perbedaan latar lingkungan alam dan budayanya, ruang bersama masyarakat perlu ditelaah. Hasil telaah menunjukkan bahwa dengan adanya penyesuaian dengan kondisi lokal, ruang bersama masyarakat Tambakrejo secara umum adalah tanean, teras atau emper, ruang depan atau balai, dapur, langgar, dan ruang antar bangunan.

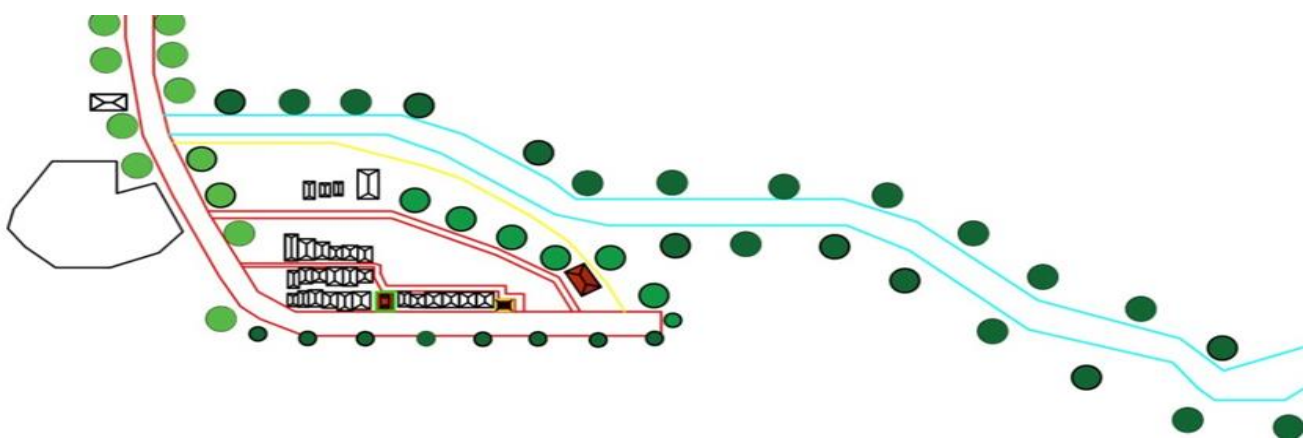

Gambar 3. Lay out dukuh Tambakrejo, Desa Tambakrejo Kecamatan Sumbermanjing Wetan Kabupaten Malang 
Dalam skala permukiman, masjid, jalan, warung menjadi ruang bersama pada waktu tertentu. Pola permukiman yang terjadi di Dukuh Tambakrejo yakni pola Tanean Lanjeng yang mana pola tersebut mengikuti arah jalan atau berderet, tanean merupakan ruang bersama pada masyarakat Madura. Tanean Lanjeng merupakan bentuk pemukiman tradisional masyarakat Madura terdiri atas kumpulan rumah dari beberapa keluarga masih terikat dalam satu sanak keluarga. Jarak antara satu rumah dengan rumah lainnya pun cukup dekat, hanya dibatasi oleh pekarangan. Tanean Lanjeng terjadi karena sejumlah rumah di tata berjajar dengan rumah induk yang berada di tengah-tengah komplek.

Umumnya, rumah utama ini ditandai dengan bentuk hiasan balok nok di atap berupa jengger ayam dengan posisi berhadap-hadapan seperti konfigurasi batu nisan pada sebuah makam. Hiasan model ini sebagai refleksi diri penghuni rumah pada kematian. Rumah utama ini ditempati oleh orang tertua pada keluarga. Orang tua ini memiliki istilah kepala somah. Analogi raja kecil, kepala somah adalah yang menguasai semua kebijakan keluarga, seperti masalah perkawinan yang akan dilakukan. Penyusunan rumah disusun berdasarkan tingkatan dalam keluarga. Arah Barat sampai timur adalah arah yang menunjukkan urutan dari tua hingga muda. Ikatan kekeluargaan menjadi sangat erat berkat diberlakukan sistem tersebut, sedangkan hubungan antar kelompok cenderung menipis, karena letak pemukiman yang diaspora terpisah oleh karena luasnya tanah Madura dan sedikitnya penduduk. Di sisi lain, ujung paling barat merupakan letak musholla atau langgar. Sementara itu susunan barat hingga timur terletak rumah orang tua, anak anak, cucu hingga cicit dari keturunan dari pihak wanita. Kelompok keluarga seperti itu disebut sebagai koren atau rumpun bambu. Istilah tersebut sesuai karena satu koren berarti satu keluarga inti. Rumah adat Madura hanya memiliki satu pintu di bagian depan. Hal tersebut dimaksudkan agar pemilik rumah dapat memeriksa aktivitas keluar masuk anggota keluarga. Pintu tersebut dihiasi ukiran-ukiran asli Madura, dengan komposisi hijau dan merah yaitu lambang kesetiaan dan perjuangan pahlawan. Sebuah gambar lukisan bunga juga biasanya menghiasi dinding bagian depan rumah. Lukisan tersebut seperti melambangkan keharmonisan keluarga. Bagian dalam rumah berdiri 4 buah kolom penyangga menggunakan kayu Jati. Kolom-kolom ini terhubung satu dengan lainnya, sehingga membentuk yang disebut dengan pilar pasarean.

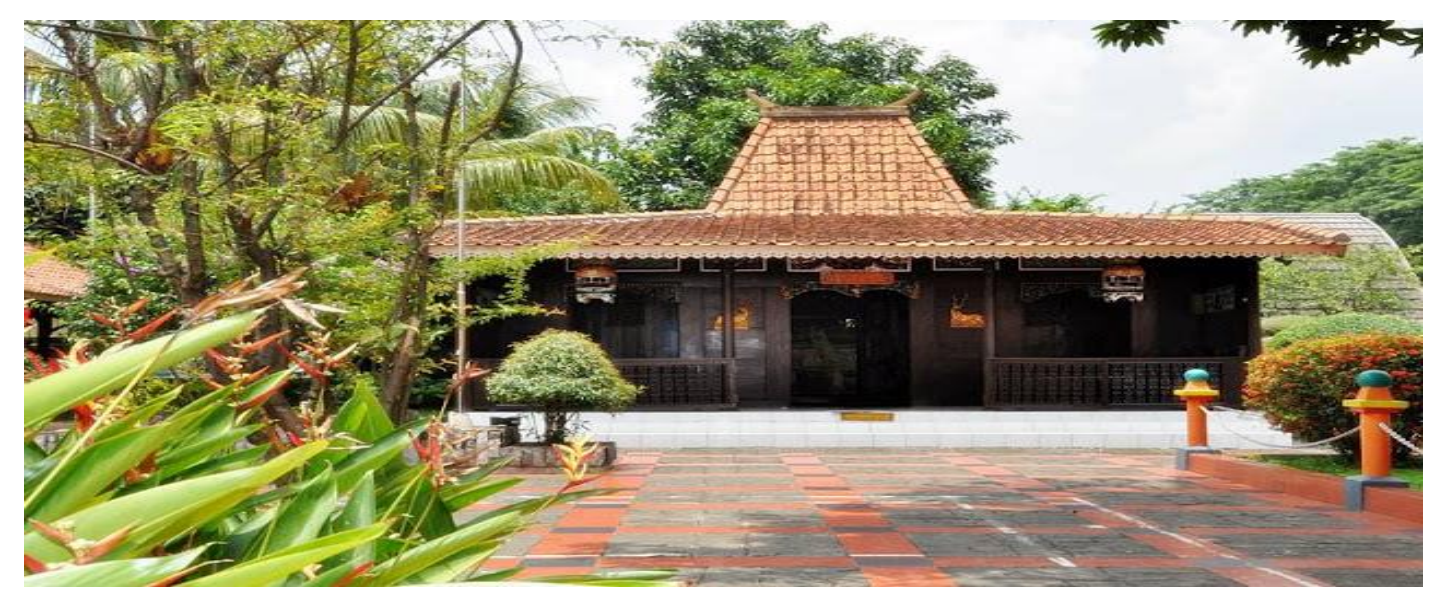

Gambar 4. bentuk rumah tonghuh sebagai induk pada pola pemukiman tanean Lanjeng 


\section{Proses terbentuknya permukiman Tanean Lanjeng}

Awal terbentuknya rumah induk disebut dengan tonghub atau rumah leluhur suatu keluarga. Tonghuh dilengkapi dengan kandang, langgar, dan dapur. Apabila sebuah keluarga memiliki anak yang sudah berkeluarga, khususnya anak perempuan, maka orang tua harus membuatkan rumah bagi anak perempuan. Penempatan rumah untuk anak perempuan berada pada posisi di sebelah timur. Kelompok pemukiman yang demikian disebut pamengkang, begitu juga bila generasi berikutnya Bentuk demikian terus menerus berkembang dari waktu ke waktu.

Jika susunan ini terlalu panjang, maka susunan berubah menjadi berhadapan. Urutan susunan rumah tetap dimulai dari ujung barat kemudian berakhir di ujung timur. Pertimbangan ini dikaitkan dengan terbatasnya lahan pertanian, sehingga sebisa mungkin tidak mengurangi lahan pertanian yang ada. Jadi, untuk mengidentifikasi satu alur keturunan dapat dikenali melalui susunan penghuni rumahnya. Generasi terpanjang dapat dilihat sampai dengan lima generasi yaitu di tanean Lanjeng. Posisi tonghuh selalu ada di ujung barat sesudah langgar.
Langgar selalu berada di ujung barat sebagai akhiran masa bangunan yang ada. Susunan rumah tersebut selalu berorientasi utara ke selatan. halaman di tengah inilah yang disebut tanean lanjeng.

Pada saat masyarakat Madura perantauan, mereka membawa tradisi berhuni dan mengadaptasi latar lingkungan alam dan lingkungan budayanya. Dengan adanya adaptasi dengan latar lingkungan dan budaya, permukiman di Dusun Tambakrejo Desa Tambakrejo Kabupaten Malang memiliki perbedaan dengan yang ada di Madura. Pengadaptasian tersebut merupakan suatu usaha keberlanjutan. Begitu pula dalam keberadaan ruang bersamanya, yang mengalami penyesuaian.

Namun untuk di Dusun Tambakrejo permukiman Tradisonal Suku Madura dalam hal ini bentuk hunian berupa rumah tradisional telah di kombinasikan dengan budaya Jawa Timur dikarenakan bentuk hunian suku madura bersumber atau berakar dari kebudayaan masyarakat Jawa sehingga bentuk hunian trdaisonal suku madura di modifikasi dengan menerapakan bentuk hunian tradisional masyarakat Jawa yakni rumah Joglo.

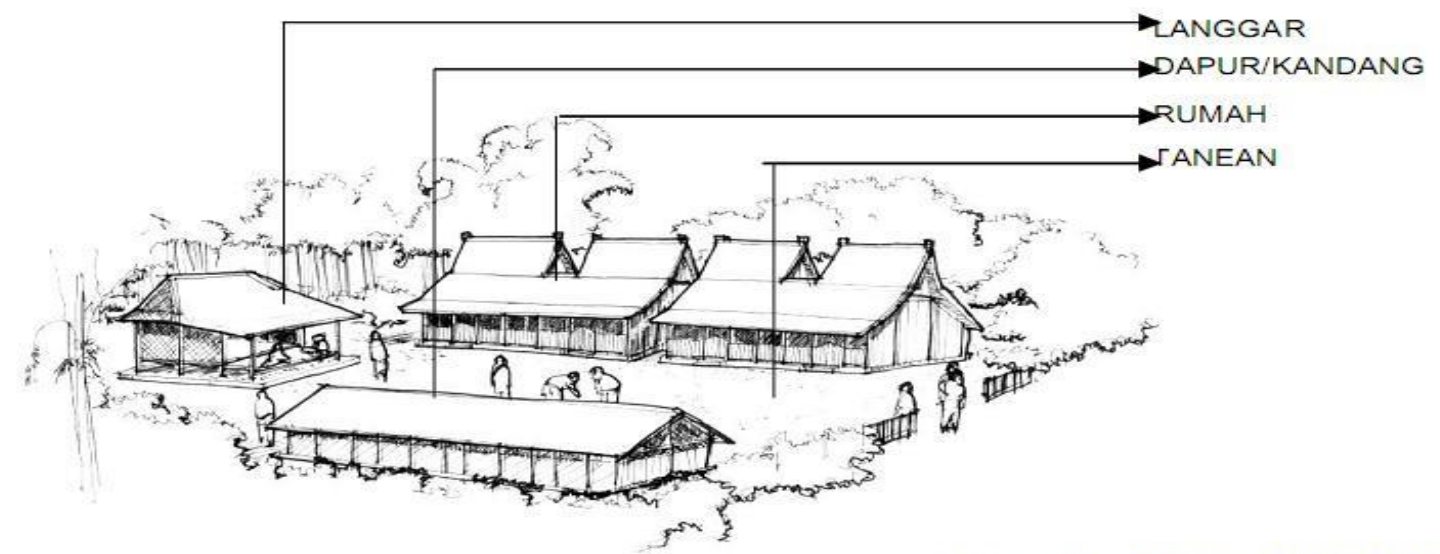

PERSPEKTIF TANEAN

Gambar 5. Perspektif Tanean Lanjeng

Sumber : rumah Adat Madura / wisatamadura.or.id 


\section{Elemen Pembentuk Lanskap}

Elemen pembentuk lanskap pada permukiman Dukuh Tambakrejo Desa Tambakrejo Kabupaten Malang yakni meliputi sumber daya alam dan sumber daya budaya. Sumber daya alam misalnya sungai dan laut, vegetasi, tanah lahan pertanian dan perkebunan, hutan, bangunan, jalan atau akses dan iklim. Sedangkan sumber daya budaya berupa adanya ritual petik laut dan syukuran nelayan.

\section{Pola Tata Ruang Permukiman Tradisional}

Berdasarkan hasil penelitian yang dilakukan bahwa pola tata ruang yang ada pada permukiman tradisonal Desa Tambakrejo Kecamatan Sumbermanjing wetan Kabupaten Malang yakni berupa tata ruang makro, tata ruang mikro dan tata ruang meso.

a. Tata Ruang Makro

Ruang makro adalah ruang lanskap yang mendukung pada seluruh kehidupan masyarakat berupa ruang hutan, ruang pemukiman, ruang pertanian dan perkebunan, dan ruang peternakan. Ruang hutan berada pada lahan dengan tofografi dataran rendah dan dataran tinggi. Ruang pemukiman adalah ruang dimana tempat bermukim masyarakat Desa Tambakrejo, khusunya Dusun Tambakrejo. Ruang pertanian berupa sawah, ladang dan perkebunan yang ada di sekitar lokasi pemukiman msyarakat sekitar. Sedangkan untuk peternakan, masyarakat Desa Tambakrejo, khusunya Dusun Tambakrejo menggunakan kandang dan jarang untuk melepas ternaknya di berada diluar kandang.

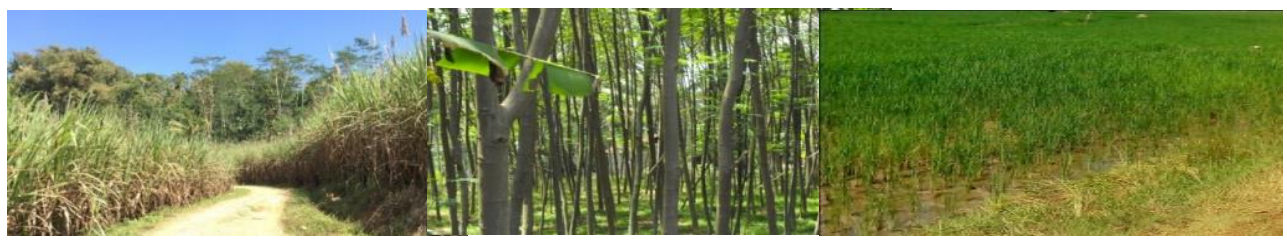

Kebun tebu, sengon dan sawah di lokasi tapak

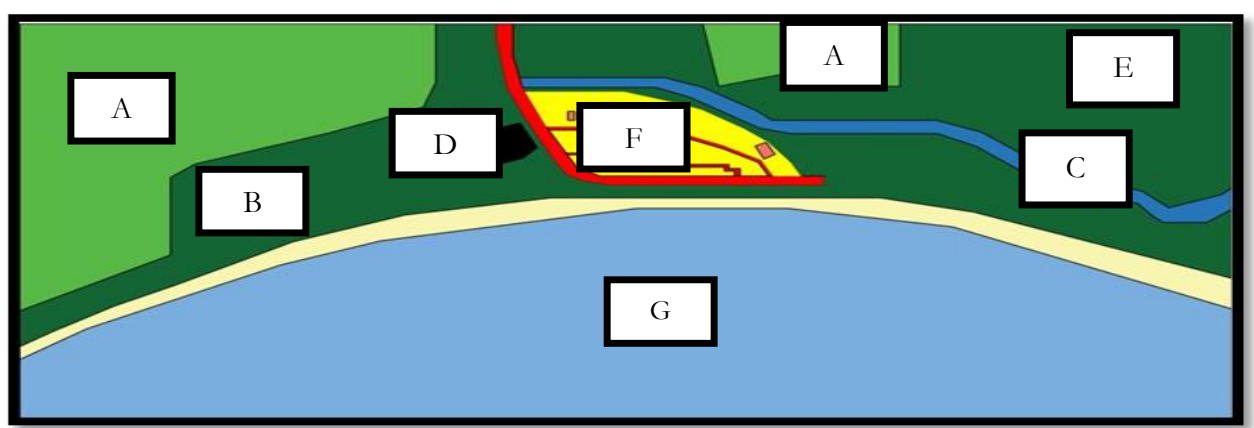

Gambar 6. Tata ruang makro

Keterangan :

A = Ladang/sawah

$\mathrm{B}=$ Kebun Tebu

$\mathrm{C}=$ Sungai

$\mathrm{D}=$ Makam

$\mathrm{E}=$ Hutan Sengon

$\mathrm{F}=$ Arsitektur Tradisional

$\mathrm{G}=$ Laut 
b. Tata Ruang Meso

Ruang meso merupakan bagian dari ruang makro yang terdiri dari lingkungan permukiman masyarakat, ruang ini terdiri dari elemen-elemen pembentuk lanskap pemukiman yaitu, hardscape berupa bangunan hunian dan jalan atau akses serta kuburan umum dan softscape berupa vegetasi, sungai dan laut - Untuk pola permukiman dan penyebaran rumah atau hunian di Dukuh Tambakrejo desa Tambakrejo sebagian besar berkelompok mendekati sumber mata pencaharian atau dekat lahan pertanian dan mengikuti pola linier atau berderet disepajang jalan mengikuti pola jalan di wilayah tersebut. Jarak antar rumahpun tidak terlalu jauh dan saling berdekatan yang hanya di pisahkan oleh pekarang atau halaman.

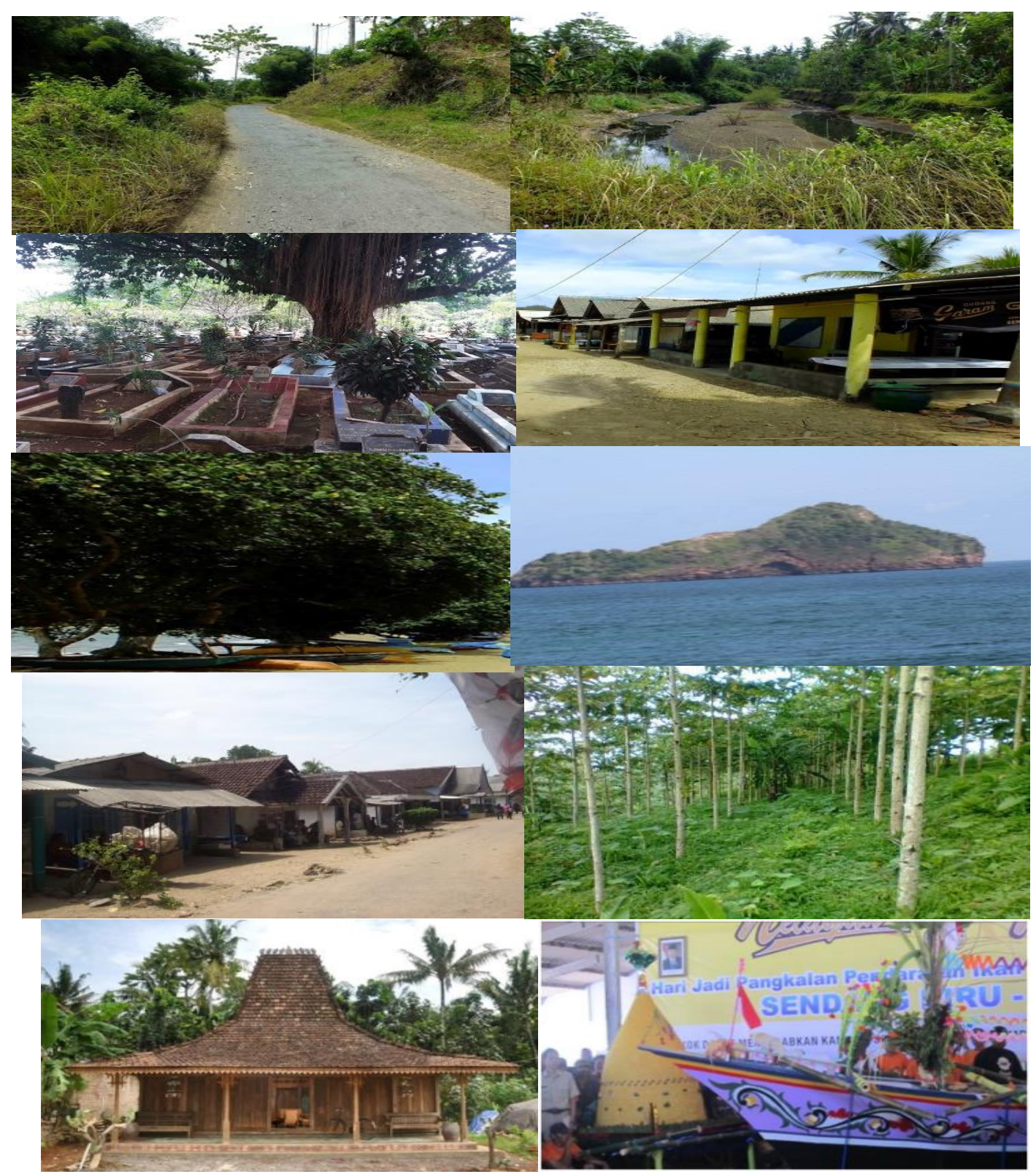

Gambar 7. Elemen pembentuk lanskap pada tata ruang meso 


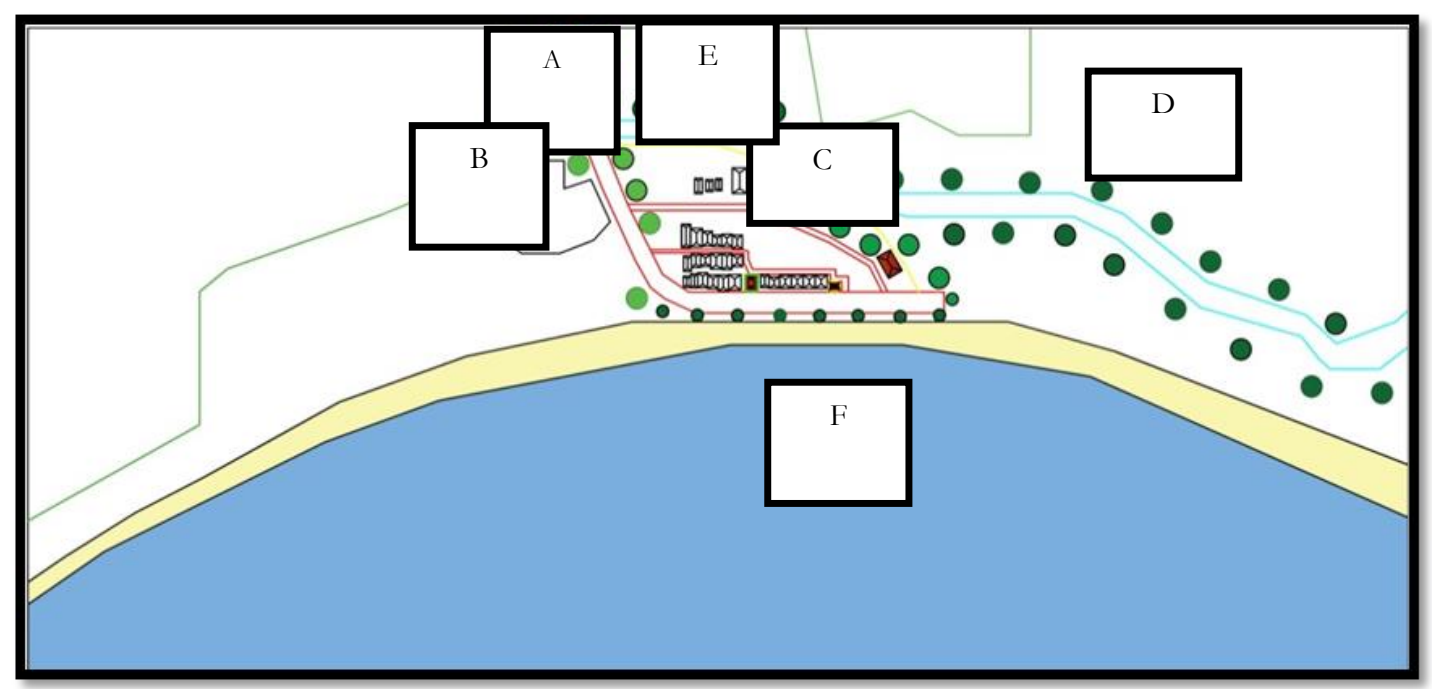

Gambar 8. Denah bentuk tata ruang meso

Keterangan :

$A=$ Akses menuju desa Tambakrejo

$\mathrm{B}=$ Makam

$\mathrm{C}=$ Permukiman warga dan berarsitektur tradisional

$\mathrm{D}=$ Sungai

$\mathrm{E}=$ Vegetasi

$\mathrm{F}=$ Laut

\section{c. Tata Ruang Mikro}

Ruang mikro adalah bagian dari ruang permukiman masyarakat yang meliputi bagian pekarangan rumah dan bentuk rumah. Bentuk tata ruang dari rumah masyarakat dukuh Tambakrejo, Desa Tambakrejo Kecamatan Sumbermanjing Wetan Kabupaten Malang mengikuti bentuk kepercayaan dan filosofi dari rumah tradisional madura yang kemudian dikombinasikan dengan rumah tradisonal Jawa yakni rumah tradisonal Joglo yakni pendopo, pringgitan dan dalem (ruang utama), sentong, gandhok. Pembagian zonasi ruang dalam sebuah rumah yakni dengan menyesuaikan banyaknya anggota keluarga yang tinggal di dalamnya. Bentuk dan fungsi pembagian tata ruang pada rumah tradisional masyarakat Jawa yaitu sebagai berikut :
1. Pendopo

Tidak seperti rumah gadang, joglo memiliki ruang terbuka di bagian depan rumah yaitu pendopo. Desain terbuka yang diterapkan merupakan simbol penyatuan dengan alam sekitar. Meski demikian tidak sembarang orang boleh melintasi pendopo untuk masuk ke dalam rumah. Ada jalan masuk dan keluar rumah khusus yang letaknya terpisah dari pendopo. Fungsi pendopo dalam rumah joglo antara lain tempat menerima tamu, mengadakan pertemuan, upacara adat, dan menggelar kesenian dan hiburan seperti tarian dan wayang kulit. 
2. Pringgitan

Ruangan ini merupakan penghubung pendopo dan rumah dalam. Bagian ini dipergunakan tempat pertunjukan wayang kulit. Wayang dalam bahasa Jawa juga disebut ringgit. Maka dari kata ringgit muncul istilah pringgitan.

\section{Dalem (ruang utama)}

Ruangan ini adalah bagian utama rumah joglo. Digunakan sebagai tempat berkumpul anggota keluarga untuk bersantai dan bercengkerama. Selain omah njero terdapat omah mburi, dan dalem ageng.

\section{Sentong}

Sentong merupakan tempat beristirahat atau kamar bagi keluarga penghuni rumah. Sentong terbagi ke dalam 3 bagian, yaitu:

\section{a. Sentong Tengen}

Sentong tengen atau kamar yang berada di bagian kanan merupakan bagian untuk kamar keluarga atau anakanak. Selain untuk kamar tidur, tempat ini sebagai tempat menyimpan bahan makanan.

b. Sentong Kiwo

Selain sentong tengen, joglo Situbondo mempunyai sentong kiwo di sebelah kiri. Bagian ini digunakan sebagai tempat tidur orang tua atau kerabat sesepuh. Ruangan ini biasanya terhubung dengan ruang belakang yang memisahkan dengan dapur.

\section{c. Sentong Tengah}

Bagian ini dianggap sakral bagi masyarakat Jawa Timur. Biasanya ruang tengah diberi penerangan berupa pelita yang menyala sepanjang waktu. Di dalamnya terdapat cermin dan sisir dari tanduk binatang serta memiliki hiasan berupa keris.

\section{Gandhok}

Selain rumah utama, ada bangunan tambahan memanjang di bagian belakang yang disebut gandhok. Bagian ini digunakan tempat penyimpanan barang atau bahan makanan.

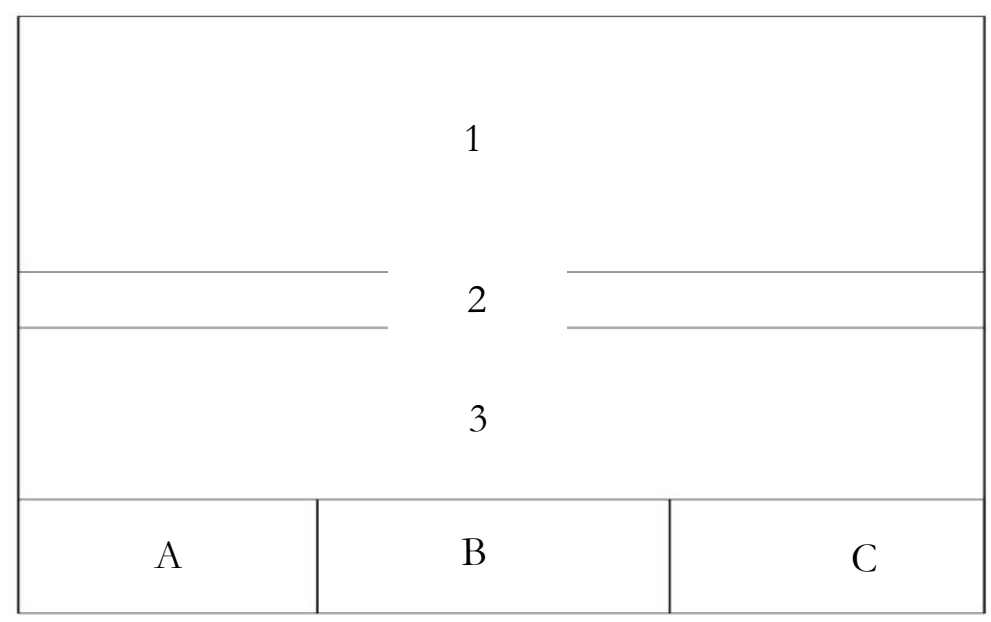

Gambar 9. Denah rumah joglo rakyat biasa

Keterangan

1. Pendapa

2. Pringgitan

3. Omah Njero : a. Sentong kiwa b. sentong tengen c. Senthong tengah

4. Gandhok 


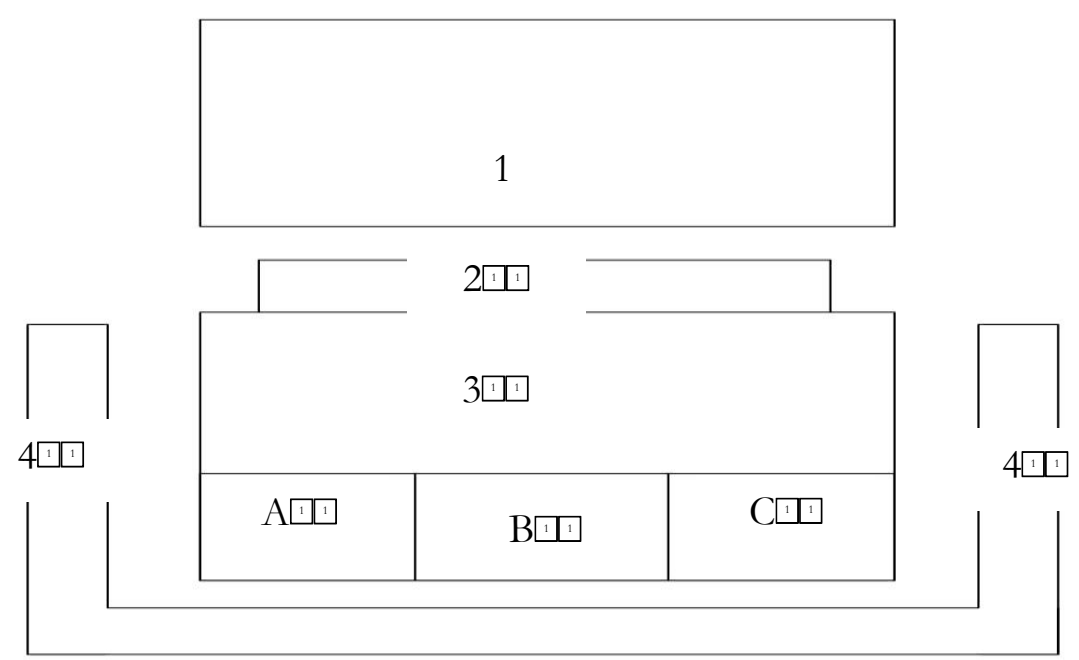

Gambar 10. Denah rumah joglo bangsawan

Keterangan

1. Pendapo

2. Pringgitan

3. Omah Njero : a. Sentong kiwa b. sentong tengen c. Senthong tengah

4. Gandhok

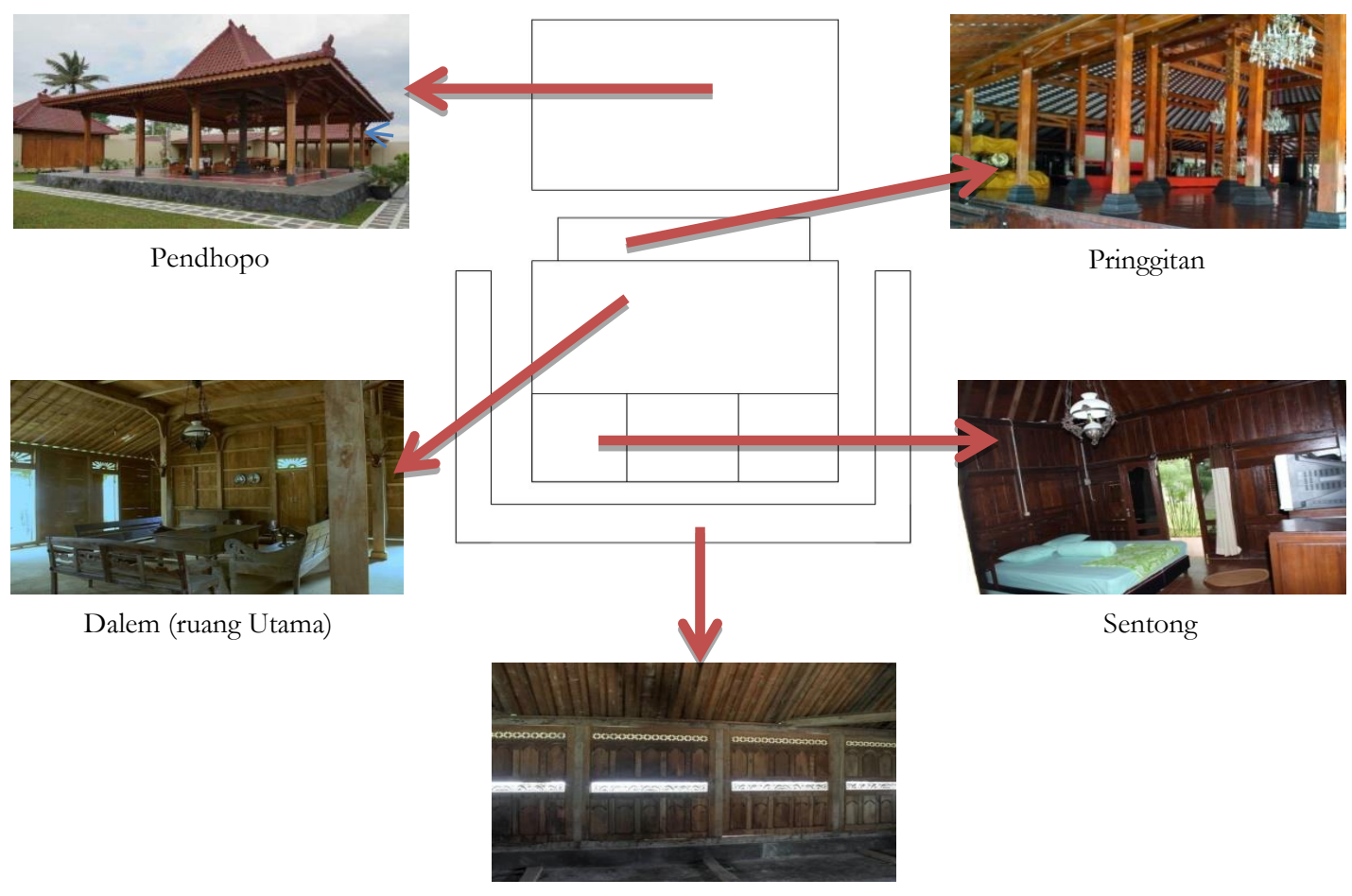

Gandhok

Gambar 11. Bagian ruang mikro rumah tradisional jawa yang di adaptasi masyarakat kawasan pantai sendiki 

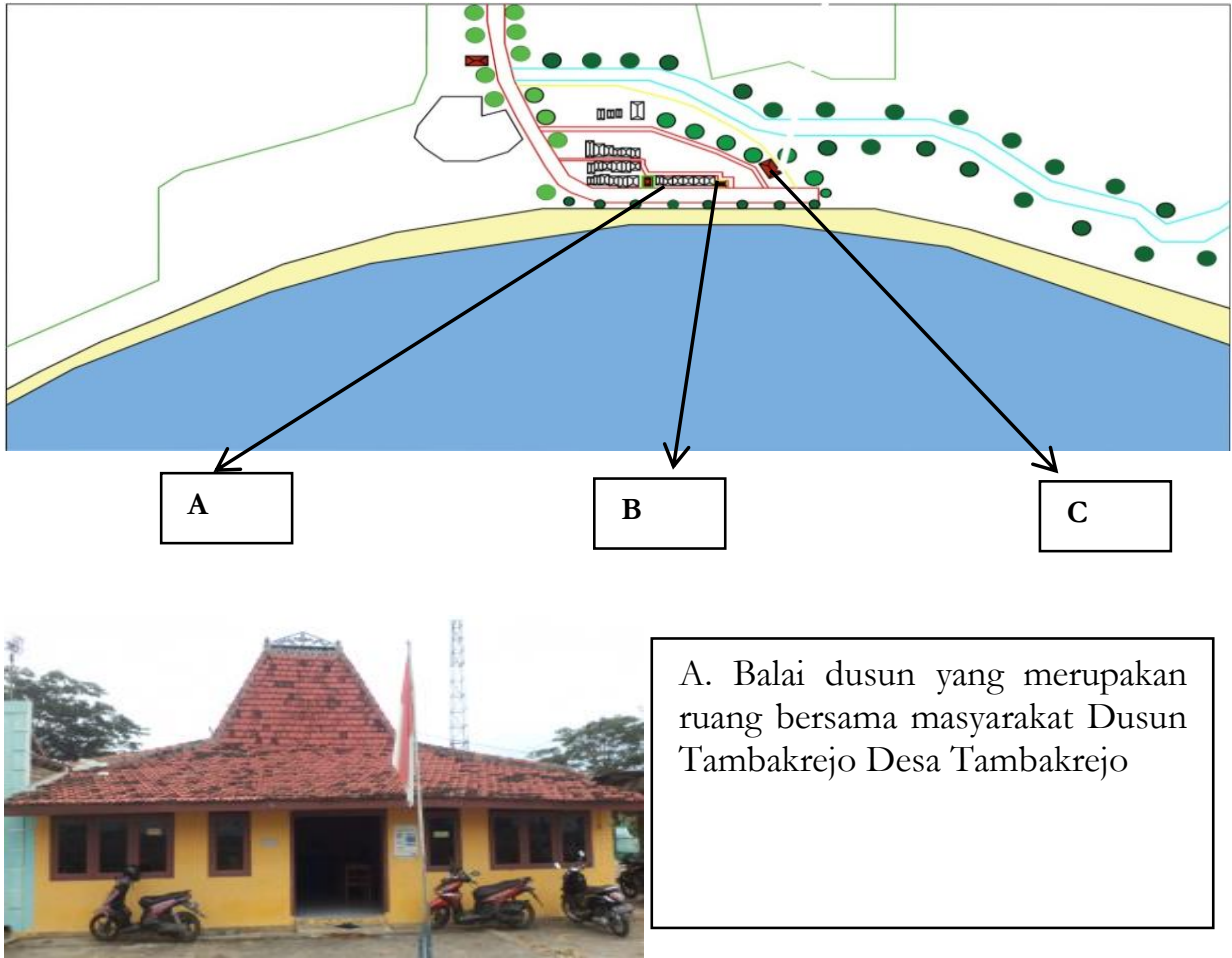

A. Balai dusun yang merupakan ruang bersama masyarakat Dusun Tambakrejo Desa Tambakrejo

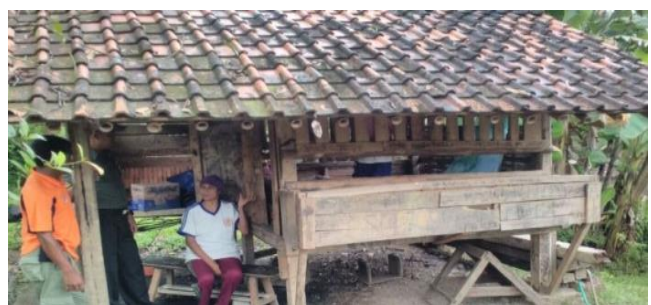

B. Kandang ternak masyarakat Dukuh Tambakrejo, Desa Tambakrejo

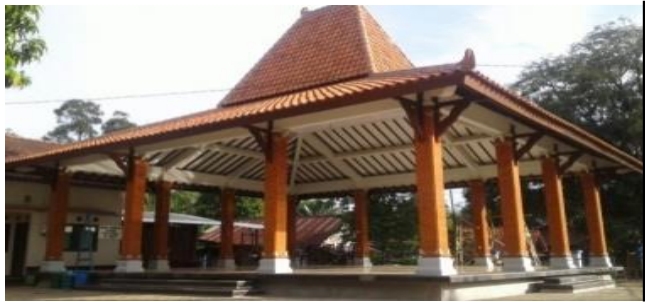

C, Aula yang digunakan masyarakat sebagai ruang bersama untuk kegiatan yang dilakukan oleh Desa

Gambar 12. ruang bersama masyarakat Dusun Tambakrejo, Desa Tambakrejo

Yang menjadi keunikan pada pemukiman tradisional Dukuh Tambakrejo ini yakni di tengah-tengah permukiman warga yang berderet sepanjang jalan dengan bentuk hunian seperti rumah tadisional Madura yakni tanenan Lanjeng terdapat balai dusun dan aula di bagian barat pemukiman yang dijadikan ruang bersama masyarakat ketika ada acara bersih desa atau acara- acara lainnya seperti syukuran nelayan dengan bentuk bangunannya yakni rumah joglo, sedangkan untuk kandang ternak terdapat di bagian belakang pemukiman warga yang mana tidak mengadopsi sepenuhnya pola hunian tanenan Lanjeng yang mana di bagian depan rumah terdapat kandang ternak. 


\section{Kesimpulan}

$\begin{array}{ccc}\text { Pola } & \text { ruang sosial atau } \\ \text { permukiman } & \text { tradisional pada }\end{array}$ masayarakat Dusun Tambakrejo sangat di pengaruhi oleh kondisi lingkungan seperti kondisi fisik lingkungan maupun kondisi nonfisik lingkungan seperti iklim, vegetasi, mata pencaharian masyarakat dan struktur ruang permukiman selain itu di pengaruhi pula oleh kecendrungan aktifitas bersama masyarakat dalam keseharianya, sehingga berpengaruh pula pada intensitas pengguna ruang bersama seperti ruang makro, meso dan mikro, yang mana pada permukiman tradisional sedikit mengalami perubahan dari pola tradisional suku Madura ke pola tradisional masyarakat setempat yakni pada ruang peternakan (kandang) yang mana ruang peternakan (kandang) pada pola permukiman tanean Lanjeng berada di bagian depan hunian sedangkan pada pola permukiman masyarakat setempat ruang ternaknya (kandang) berada di bagian belakang permukiman.

\section{Daftar Pustaka}

Burhan, I., Antariksa, \& Meidiana, C. 2008. Pola Tata Ruang Permukiman Tradisional Gampong Lubuk Sukon, Kabupaten Aceh Besar, Arsitektur e - Journal, Volume1 Nomor 3, November 2008.

Hastijnti, 2005. Pengaruh ritual corak terhadap permukiman Tradisional Madura. Jurusan Teknik Arsitektur, Fakultas Teknik Sipil dan Perencanaan - Universitas Kristen Petra.

http://puslitpetra.ac.id/puslit/jour nals/.

Sasongko, I. 2005. Struktur Ruang Permukiman Karangsalah dan Segenter di Desa Bayan. Jurnal
Dimensi Teknik Arsitektur. 20 (1) : 16-25.

Wiryoprawiro, Z. M. 1986. Arsitektur Tradisional Madura Sumenep dengan Pendekatan Historid dan Deskriptif, Surabaya: Laboratorium Arsitektur Tradisional, FTSP-ITS. 